\title{
Spirituality: The Legacy of Parapsychology
}

\author{
Harald Walach $^{\mathrm{a})}$, Niko Kohls ${ }^{\mathrm{b})}$, Nikolaus von Stillfried ${ }^{\mathrm{c}}$, \\ Thilo Hinterberger ${ }^{c)}$, Stefan Schmidt ${ }^{c)}$ \\ a) Division of Psychology, School of Social Sciences, The University of Northampton, \\ Park Campus, Boughton Green Road, Northampton NNZ 7AL, UK \\ E-mail: harald.walach@northampton.ac.uk \\ b) Generation Research Project, Human Science Centre, \\ Ludwig-University-Munich, Munich, Germany \\ c) University Medical Centre, Institute for Environmental Medicine and \\ Hospital Epidemiology, Freiburg, Germany
}

Received: August 2008; accepted: 27 December 2008

\begin{abstract}
Summary
Spirituality is a topic of recent interest. Mindfulness, for example, a concept derived from the Buddhist tradition, has captivated the imagination of clinicians who package it in convenient intervention programs for patients. Spirituality and religion have been researched with reference to potential health benefits. Spirituality can be conceptualised as the alignment of the individual with the whole, experientially, motivationally and in action. For spirituality to unfold its true potential it is necessary to align this new movement with the mainstream of science, and vice versa. Hence, both a historical review, and a systematic attempt at integration is called for, which we are trying to give here. It is useful to go back to one of the roots: parapsychology. Parapsychology was founded as a counter movement to the rising materialist paradigm in the 19th century. Adopting the methods of the natural sciences, it tried to prove the direct influence of consciousness on matter. After 125 years this mission must be declared unaccomplished. Surveying the database of parapsychological research it is obvious that it will not convince sceptics: Although there are enough exceptional findings, it has in general not been possible to reproduce them in replication experiments. This is, however, a characteristic signature of a category of effects which we call effects of generalised entanglement, predicted by a theoretical model analogous to quantum theory. Using this perspective, parapsychological effects can be understood, and the original aim of the founding fathers can be recovered, as well as a new, systematic understanding of spirituality be gained. Generalised entanglement is a formal and scientific way of explaining spirituality as alignment of an individual with a whole, which, according to the model, inevitably leads to non-local correlations.
\end{abstract}

\section{Keywords}

spirituality, parapsychology, history of psychology, consciousness, non-locality, weak quantum theory 


\section{Background: Spirituality and the History of Parapsychology}

\section{Spirituality}

The mainstream of science is following a materialist paradigm, at least implicitly. Following Collingwood, who was one of the major sources for historian of science Thomas Kuhn in his attempt to understand conceptual revolutions (Toulmin, 1985), it is important to realise that such absolute presuppositions are extremely powerful, and yet quite unnoticed and usually unreflected (Collingwood, 1998, orig. 1940). The common mainstream consensus, at least in large compartments of science, but probably also in the humanities and in psychology, is that matter is primary and mental entities derivate. This entails that mental events, conscious experience and thus all inner experiences such as spiritual or religious experiences are secondary to and derived from, the material events happening in the brain (Damasio, 2000; Dennett, 1991). This means, however, that much of what has been reported as spiritual or religious experiences, together with the implicit noetic quality of gaining knowledge of or access to a transcendent reality (James, 1985), can only be incorporated into the current scientific paradigm as the quite innocent musings of a complex neuronal system idling and keeping itself company, while doing nothing (Walach, 2007). If the thought is followed to its very end, spirituality and spiritual experiences can only be conceptualised as inner states of a neuronal system without any reference to an outer, objective reality. This view fits neatly with the current neuroscientific understanding that most of the brain's activity is generated by internal processes anyway and reference to outside stimuli is only modulating this ongoing activity (Raichle, 2006). Hence, using current mainstream understanding as a reference point, spirituality might be interesting, but only as something that modulates inner states, could be helpful for homeostatic balance or as generic resource for a complex neuronal system. A modern scientific understanding will have no conceptual place, let alone warm feelings for a concept of spirituality that postulates a transcendent reality and some contact or reference to it, be it as experience or otherwise.

Yet spirituality has as a common definitional core some experiential, notional, behavioural or intentional relationship with some transcendent reality, out of which arises meaning, solace or motivation for an individual. There is a lot of debate within religions as to how to interpret this transcendent reality, which we have no intention to enter into. Some call it God and imbue it with features of personality, such as love and forgiveness. Some do not talk 
about God at all but about Unity, or use contradictory terms such as fullness and emptiness to describe ultimate reality. And the attempts at conceptualising it are endless (Ferrer, 2002). However, even if one finds spiritual fulfilment in being related to a family, the larger social whole, or the planet, without any reference to a spiritual entity, there would still be a relationship to a reality transcending the immediate goals of an individual. Hence, transcendence might be the smallest common denominator of different concepts and definitions of spirituality. We are going to propose another definition, which we will elaborate on in later parts of this article. It conceptualises spirituality as alignment of the individual with the whole. Here, the Whole would be a transcendent reality as well.

Interestingly, in recent years spirituality has become a topic of interest mainly for clinicians, but also for psychologists of religion. Clinicians discovered that using approaches derived from Buddhist meditation practice, such as mindfulness, can be clinically effective (Grossman, Schmidt, Niemann, \& Walach, 2004; Segal, Williams, \& Teasdale, 2002; Williams, Teasdale, Segal, \& Kabat-Zinn, 2007). Psychologists find that mindfulness might be an important concept to understand how the mind functions, because the "wandering mind" or the default network of the brain might be crucial for understanding fundamental processes from memory to attention (Mason et al., 2007; Smallwood \& Schooler, 2006), and it might also be central for well-being and happiness (Wallace \& Shapiro, 2006). In psychology we observe a veritable trend towards "Buddhist Psychology" (Docket, Dudley-Grant, \& Bankart, 2003). At the same time, from the point of view of a more traditional psychology of religion approach a lot of findings have been amassed that point to the potential health benefits of classical religions and spirituality (Koenig, 1998; Koenig, McCullough, \& Larson, 2001; D.B. Larson \& Larson, 2003). On the political front in the United States, we see a growing divide between fundamentalist concepts of religion and science, where scientists seem to be largely a-religious or agnostic (E.J. Larson \& Witham, 1998), and religious crusaders adopt antiscientific standpoints using political power and economic influence. Also, the recent threats of international terrorism cannot be decoupled from the apparent divide between the post-modern scientific and secular culture of the West implicitly denying any relevance to a transcendent reality, and more traditional approaches.

Our diagnosis of the problem is: at the heart of the matter is a lack of understanding of spirituality as a prime human motive by the mainstream of science as well as the apparent incompatibility of various concepts of spirituality and religion with what is generally taken to be the scientific view of the world. In 
what follows, we would like to contribute to this debate. We think that in order to understand the issues properly, it is useful to revisit the history of one attempt to integrate some approaches to the transcendent into science: parapsychology. This will teach us a lot about what will not work and about how one might approach the question. We will then use the findings of this analysis to propose a completely new systematic approach. This will lead us to taking the issue of spirituality to the very heart of the scientific enterprise, the formal theory of matter. It is here that we find the remedy for the ailment. Out of a generalised version of Quantum Theory it is possible to recover a scientifically sound notion of spirituality. This is the alignment of the individual with the whole as a form of generalised entanglement predicted by a theory, which is modelled along the lines of Quantum Theory proper: Weak Quantum Theory.

\section{The History of Parapsychology}

When the Society for Psychical Research (SPR) was founded in 1882 its mission was to find scientific, empirical evidence to disprove the claim of materialism according to which all phenomena must ultimately submit to the laws governing matter. The founding document states:

.... It has been widely felt that the present is an opportune time for making an organised and systematic attempt to investigate that large group of debatable phenomena designated by such terms as mesmeric, psychical and spiritualistic. From the recorded testimony of many competent witnesses, past and present, including observations recently made by scientific men of eminence in various countries, there appears to be, amidst much illusion and deception, an important body of remarkable phenomena, which are primâ facie inexplicable on any generally recognised hypothesis, and which, if incontestably established, would be of the highest possible value (Society for Psychical Research, 1882, p. 3).

This stance is quite understandable given the mood of the time. In 1842 Emil du Bois-Reymond (1818-1896), together with a couple of other young scientists-among them the physicist and physiologist Hermann von Helmholtz (1821-1894), and the physiologist Ernst Brücke (1819-1892) — came together and made a pledge. Du Bois-Reymond described this in a letter to one of his closest friends, Anton Hallmann (1812-1888) in the following way:

Brükke (sic) and I, we have pledged to bring to light the truth that there are no other forces active in the universe than the general physical-chemical ones. Furthermore, where those are not sufficient to explain things so far, these explanations will 
either have to be sought following the physical-mathematical method, or found by assuming new forces. These new forces, however, are to be always reduced to attracting and repulsive components and would be of the same dignity and nature as the physical-chemical ones, and thus inherent in matter." (Du Bois-Reymond, 1918, p. 108, transl. HW).

This document, describing a clandestine pact of what were to be the most famous minds in the German natural sciences in the second half of the 19th century, is a window into the zeitgeist out of which the parapsychological movement arose (Paul, 1984; Sonntag, 2001). It is important to note the following few facts in order to understand the exemplary nature of this document well: Du Bois-Reymond, Helmholtz and Brücke received their academic training from the physiologist Johannes Müller (1801-1858), who was a trained physiologist, anatomist and marine biologist but also one of the most famous natural philosophers of the first half of the 19th century. Although Müller can be regarded as the founding father of modern physiology, he was actually championing a vitalistic standpoint which was later frequently criticized as "physical" or "physiological" idealism. Müller was inclined to deny that our sensations are images of objective reality. However, while Müller's vitalistic physiology naturally gravitated towards idealism, his disciples committed themselves to proving a strict materialistic standpoint by means of experimentally scrutinizing physiological mechanisms. This characteristic change in the epistemological stance of Müller's most prominent disciples building the intellectual backbone of the next generation of scientists is not only the replacement of the structuralist paradigm of anatomy with the new functionalist paradigm of physiology, but also the watershed which separated the natural sciences from their vitalistic grounding derived from Naturphilosophie (Lenoir, 1989). Their scientific achievements seemed to justify their move: Whereas Müller had seen the nerve impulse as a prime example of a vital function but had never subjected it to experimental investigation, Helmholtz was able to experimentally determine the speed of nerve impulses, which he found to be remarkably slow with 90 feet (27 metres) per second. This slow velocity suggested that not a mysterious life force but actually natural elements were responsible for the eliciting and transporting of sensations. In a similar vein, du Bois-Reymond and Brücke, who later became the founding father of the Viennese school of physiology and was to be the direct teacher of Sigmund Freud in Vienna, were also campaigning for a materialistic view.

By the time the Society for Psychical Research was founded, the intellectual climate in Europe, at least in the natural sciences, had become materialist in 
a chilly way for every spiritualist, transcendentalist, or even dualist. Small wonder that Wilhelm Dilthey, trying to find a footing for what in German became to be known as "Geisteswissenschaften"- the humanities—around the turn of the century could do nothing else than codify the dualism that had factually arisen between sciences, dealing with matter, and humanities, concerned with mental activities of humans (Dilthey, 1910 (orig. 1894); Ineichen, 1985; Treitel, 2004). And it is only against this background of materialist emphasis within the natural sciences that the founding of the SPR can be understood not only as an innocent scientific society among others, but as a counter-movement promoting a certain world-view, namely that of a nonreductionist understanding of human affairs, and of mind and consciousness in particular.

The SPR was established in England on the 20th February 1882 and was later imitated in other countries (Gauld, 1968). Men like Henry Sidgwick, Frederic W.H. Myers, Edmund Gurney, Walter Leaf as well as Lord Raleigh helped building its reputation, and famous figures like the chemist William Crookes, the writer Sir Arthur Conan Doyle, the physicist Oliver Lodge as well as the psychologists William James, Sigmund Freud, and Carl Gustav Jung became members. The SPR pledged to use scientific methods to substantiate its claims, and those were increasingly but not exclusively the methods used by the successful natural sciences. Initially, and during the first phase up to the 1930s the activities of the SPR covered large surveys, intensive case and field studies of mediums and séances, qualitative studies of precognitive dreams and the like (Bauer, 1997; Beloff, 1993; Inglis, 1977; Mauskopf \& McVaugh, 1980). With the establishment of the "Parapsychology Laboratory" at Duke University in Durham by J.B. Rhine the picture changed. He introduced experimental methodology into parapsychology, with the idea of replicable, experimental control and quantitative statistical analysis through laboratory methods: i.e. simple research paradigms that could be repeated at will (Inglis, 1984; Pratt, Rhine, Smith, Stuart, \& Greenwood, 1966; Rhine, 1964). Modern day parapsychology was born as an heir from the marriage between the original impulse to prove the existence of phenomena beyond the world view of the natural sciences, such as telepathy, clairvoyance, precognition and psychokinesis, and the successful experimental method used by the natural sciences. ${ }^{1}$ It seems a natural assumption that the child of the two should be able to do, what each one alone was not able to do.

1) It should be mentioned for the sake of completeness that not all the early or later members of the parapsychology community were or are committed to a non-materialist view of the world. 
If we judge the role of parapsychology by its impact on research, let alone on academic decision making, attribution of research funds, number of academic departments specialising in this subject matter, future career prospects of researchers, and interfaces between academia and society, we must unashamedly confess that the 125 years since the founding generation of enthusiastic, high calibre scientists vowed to prove materialism wrong have not seen the promised turn of the tide. It seems that academic and experimental parapsychology has failed to provide the long desired proof of principle for non-materialistic and in that sense paranormal phenomena.

\section{The Current State of Academic Parapsychology}

The current state of academic parapsychology can be sketched as follows: The long-time effort of the Princeton Engineering Anomalous Research (PEAR) Group did not succeed in proving their point and finally closed down in 2007 (Walach \& Jonas, 2007). A 22-year involvement in parapsychological research funded by the U.S. Government and dedicated to researching the possibilities of remote viewing for military applications came to an end in 1995 (Utts, 1996), because even though "[...] a statistically significant laboratory effort has been demonstrated in the sense that hits occur more often than chance [...] the information provided was inconsistent, inaccurate with regard to specifics, and required substantial subjective interpretation [...]" (Mumford et al., 1995). As one journalist summarised aptly: "psychic power is real, but no good for spying” (Wolf, 1995). The Duke Parapsychology Laboratory, the erstwhile home of J.B. Rhine and once the prestigious Mecca of parapsychology, has recently closed its doors. The Division of Perceptual Studies-formerly known as Division of Personality Studies under its late director Ian Stevenson - at the University of Virginia shows an ongoing commitment towards scrutinizing near-death experiences and alleged reincarnation cases. The Institute of Noetic Sciences as a non-profit organisation continues with high calibre research in the field. Apart from these centers, and a few single research individuals, there is no further academic work in the US in the sense that installed professors who are able to train $\mathrm{PhD}$ students and create a research environment are directing research programs in this field.

Examples can be found of materialists, trying nevertheless to prove the paranormal. However, in most instances one would see a strong correlation between a supernatural or at least dualist view of the world and belief in paranormal phenomena, as well as commitment to parapsychological research. 
The German institution comparable to the Duke Laboratory, the Freiburg Institute for Border Areas of Psychology and Psychological Hygiene (Institut für Grenzgebiete und Psychohygiene, e.V.), founded by the late Hans Bender (1907-1992) and once associated with a chair at the department of psychology at Freiburg University, has lost its direct contact with the university and operates as an independent research institution. However, classical parapsychology is only a small part of its work.

In the UK, the Koestler Chair of Parapsychology at the University of Edinburgh has not been replaced after the untimely death of Robert Morris (19422004) and has been downgraded to two lecturer positions. Nevertheless Morris managed to train several $\mathrm{PhD}$ students that were able to install active research programs related to parapsychology at a handful of US and some UK based academic institutions. The Centre for the Study of Anomalistic Psychic Processes (CSAPP) at the University of Northampton is, apart from the Koestler chair, the only acknowledged academic institution dedicated to research in this area. Some academics at UK institutions conduct research mainly around the question how belief in the paranormal shapes people's lives and behaviours. Here we can clearly see how the mainstream paradigm mentioned earlier has impacted on the field. The guiding question here is: Parapsychological phenomena cannot be real in the first place; so how come rational beings believe in them or even research them? (Alcock, 2003; French, 2003; Hergovich, 2005)

Perhaps most widely known and highly popular are the online parapsychological experiments by Dr. Rupert Sheldrake, who is a private scholar in the good old sense of the word, funding his research from small grants and out of his own pocket, but with no systematic academic link (See for instance Sheldrake, 2001; Sheldrake \& Smart, 2000, 2003). A creative group of researchers is assembled around Prof. Dick Bierman in Holland and Prof. Hans Gerding directs the Parapsychology Institute in Utrecht. In France, the Paris based Institut Métaphysique International in Paris is a private institution dedicated to parapsychological research. A new chair for parapsychology and hypnology has been recently established at the University of Lund in Sweden, which is held by Etzel Cardeña who is a hypnosis researcher. Apart from that, there are a sizeable number of single person scholars all over the globe, in private institutions or small home-based or university labs, sometimes doing incredibly fascinating and sound work.

But a sober historical and sociological analysis has to conclude: Despite all the efforts of a lot of dedicated researchers parapsychology has not been able 
to establish itself as an academically accepted discipline within the field of science over the last 125 years (Alcock, 2003). It has failed to grasp the attention of the mainstream. It has not stopped the main paradigm, that of analyticalmaterialist analysis of the universe in terms of matter-particles and their interactions. It has not had any large scale influence on the development of psychology as a discipline recently. On the contrary: researchers most interested in the phenomena frequently come from other disciplines, such as physics, engineering, sociology. Psychologists themselves seem to be rather reluctant, and are often trying to explain psychical experiences within the ruling paradigm, reducing such reports either to mistakes in perceptions, hallucinations, or social psychological phenomena of suggestion, compliance, group pressure and distortions of experience (French, 2003; Wiseman \& Morris, 1995; Wiseman \& Schlitz, 1997).

\section{From Parapsychology to Spirituality}

From today's perspective it looks like the materialist-experimental paradigm has taken over parapsychology in a subtle process of dialectical shift in history. Or in other words, parapsychology has fraternised with the erstwhile enemy, adopting its methods and presuppositions. Thereby it has lost both its thrust and its original aim. The original agenda has meanwhile been taken over by new emergent movements: by transpersonal psychology and by those researchers that are trying to understand the influence of spirituality within human life. It seems that the paranormal is often experienced in settings with a strong spiritual engagement or by people who conceptualize life in a different way. While most parapsychological experiments aim at proving the existence of the phenomena, transpersonal psychology tries to promote a deeper understanding of the principles of life and our co-existence with other beings, or it has a decidedly practical, transformative agenda (Daniels, 2005). The agenda are still the same, but the universes of discourse and debates have shifted. Spirituality (re-)emerges as the new topic and it is important to acknowledge that it was also at the base of the founding fathers' intentions in 1882. An iconographic metaphor for this change is the fact that at Duke University, whereas Rhine's prestigious parapsychology lab was recently shut down, the Center for Spirituality, Theology and Health under the auspices of Prof. Harold Koenig is thriving. 


\section{Results from Parapsychology: A Contradictory Pattern}

Viewed from a very wide distance and trying to gain a perspective over long periods, rather than single events, the pattern of results which parapsychological research has produced seem to have the following generic signature:

There are usually always very interesting initial results in any new experimental paradigm, let alone in field studies. If that had not been the case in the first place, it is hardly understandable, why some individuals should have spent a whole career trying to replicate those initial effects. One might argue, from a psychological perspective, that such strong deviations from chance expectations are normal and can happen anywhere; it is only because some researchers have a somewhat peculiar personality that they refuse to believe their later negative results (Hergovich, 2005). Although intriguingly simple, this explanation does not fit the pattern and the data. Some research projects (e.g. PEAR lab) or individual researchers (e.g. Dean Radin, Rupert Sheldrake, Ed May), produced extremely exciting data, over a long periods of time. But often the data showed a striking pattern:

1. They produced too many deviations from statistical expectation to be seen only as chance variations.

2. But those deviations were often not reproducible at will under controlled experimental conditions in replications or by others.

It is this double pattern of seemingly contradictory results that has both inspired and harassed parapsychology in nearly all cases, where strict experimental research has been employed.

We propose that this is the signature of a particular class of phenomena which we term generalised non-local phenomena (Lucadou, Römer, \& Walach, 2007). Before exploring the details we would like to illustrate that particular pattern by the following three examples of experimental paradigms which were replicated in many studies:

a) micro psychokinesis (PK) experiments where human intention alone is supposed to influence a true random number generator;

b) direct mental interaction with living systems (DMILS) experiments, where human intention is supposed to interact with the physiology or behaviour of another person under strictly controlled conditions;

c) EEG-correlation experiments where two spatially separated individuals have their EEG measured simultaneously. One participant is stimulated 
and the experimental test is, whether the non-stimulated persons show a deviation from chance in their EEG patterns at the same time.

\section{Micro-PK and the PEAR Lab Series}

Over three decades, from 1976-to 2007, the PEAR lab has produced many data that centred around one general idea: human intention may be able to influence random processes (Jahn \& Dunne, 1987). Many experimental setups were tested but one was repeated many times: A quantum process was used to produce a random series of events. A human operator was instructed to influence this process by intention only. A random sequence of zeros and ones was transformed into feedback displays that were understandable to human operators, such as a light bar that had to be voluntarily shifted up and down, or a sound sequence that had to be made higher or lower in pitch by means of intention only, or a fractional pattern of a known image that had to be completed.

The PEAR lab data were very impressive using some single, highly gifted individuals (Dunne \& Jahn, 2005; Jahn \& Dunne, 1987). They also produced deviations over time with normal operators, when enough people were sampled. Since other groups also used this type of paradigm it lent itself to a metaanalysis quite early on, which was highly significant, although the reported effect sizes were very small (Radin \& Nelson, 1989, 2003).

A new phase of the research was opened, when a three-site replication study was conducted where the PEAR lab set-up was also installed in two other, separate locations in Germany, Freiburg and Giessen. All procedures were clearly defined in an experimental protocol of what was to be the final, decisive, and largest of all studies. This study came out flat at chance expectation (Jahn et al., 2000). Interestingly, when analysed differently the data show a wide range of statistical anomalies - change in variance, change in some parameters of non-linear behaviour-that would not be compatible with pure, undisturbed random processes (Atmanspacher, Bösch, Boller, Nelson, \& Scheingraber, 1999; Nelson, Jahn, Dobyns, \& Dunne, 2000; Pallikari, 2001). The problem, however, is that the effect did not show up in the expected, a priori defined parameter that had served well previously. This effect can also be seen clearly in a more recent meta-analysis of all micro-PK experiments (Bösch, Steinkamp, \& Boller, 2006a). If all experiments are averaged, the effect of all micro-PK experiments is not statistically different from zero. However, the data-set is not homogeneous, warranting sub-group analyses. If one large experiment, which contributes significantly to the overall inhomogeneity, is 
dropped, the effect becomes significant. The debate is still ongoing, regarding the question whether the metric of that meta-analysis was correct and other details were handled well (Bösch, Steinkamp, \& Boller, 2006b; Ertel, 2007; Radin, Nelson, Dobyns, \& Houtkooper, 2006; Wilson \& Shadish, 2006). An alternative analysis, using different weights and a different method of summarising, arrives at a highly significant result (Timm, 2007). However, the precise outcome of the debate does not impact on our argument here, because the general pattern of the results is still the same: We have very strong deviations from randomness, suggesting some effect, but until now it has not been possible to pinpoint the effect by the best replication.

Taken together, the capricious idiosyncrasies found in the data pattern cast serious doubts on the appropriateness of the interpretation of PK as a classical effect of a direct causal influence of consciousness on matter. If the alleged "effect" were due to a so called classical causal mediation, (i.e. some known or unknown causal signal transfer between the participant and the random source) one would have expected that, all other relevant conditions being equal, a huge experiment would at least show the deviation with some precision, even if small. The fact that precisely this is not happening seems to be part of the signature of such effects: there is an anomaly present but this anomaly refuses to be captured by the traditional method of replication of experiments. Applying standard reasoning, one would conclude that there is nothing to investigate in the first place (Alcock, 2003). But denying what one cannot grasp is not the best of all approaches. Using a broader, perhaps also more phenomenological perspective, one would assume that there is certainly some form of anomaly present-why else do those repeatedly strong deviations from chance occur? - but this anomaly seemingly defies the net of the experimenter (Walach \& Schmidt, 2005). Using Eddington's analogy one can now ask: Are the meshes of the net too large and is this the reason why a hypothesized effect may escape? This is one traditional parapsychological strategy for excusing non-stable effects. Correspondingly, researchers have predominantly tried to react by making the meshes of the net smaller and smaller. We propose in contrast that it is not a matter of the mesh size, but rather that the traditional fishing procedure is not adequate (Lucadou, 2001; Lucadou, Römer, \& Walach, 2007), because we use a methodology geared towards causal correlations for catching non-causal correlations. To continue in the imagery of fishing: it is likely that we want to catch a somewhat peculiar quantum fish that is huge before it approaches the net, but which disappears under the coverage of the net. Once the net is taken out the fish can be found happily splashing in the water. 


\section{DMILS and the Influence of Human Intention on Human Physiology}

William Braud and Marilyn Schlitz (Braud \& Schlitz, 1983) introduced a new research paradigm into parapsychology that was meant to model experimentally distant spiritual healing. Individuals were instructed to intentionally influence another person, located at some distance. This intentional influence was to be produced according to a random scheme of activating and calming intentions, displayed on a computer screen to the agent. The dependent variable in many experiments was the electrodermal activity of the distant person as a sensitive measure of autonomic arousal. The idea behind that experimental set-up is that subtle mental influences might be measured more easily at an unconscious level. A highly successful series of experiments was published, and a meta-analysis of this first series was significant and positive (Schlitz \& Braud, 1997). At this point we decided to run a series of independent replications. We found out that some of the previous experiments did not use correct measurement methodology of the dependent variable (Schmidt \& Walach, 2000). Thus we recalibrated our system, using up do date methodology and two electromagnetically shielded chambers that controlled for classical communication. We first conducted a pilot experiment to test experimental procedures and define effect sizes and thus this study was deliberately not evaluated for statistical significance. Ironically, this pilot showed quite a sizeable effect of $\mathrm{r}=.42$ with 26 pairs, which, had we formally tested, would have been significant (Schmidt, Schneider, Binder, Bürkle, \& Walach, 2001). However, all following experiments, using the very same set-up and similar participants, were unable to replicate this initial effect (Schmidt, Tippenhauer, \& Walach, 2001; Schneider, Binder, \& Walach, 2000, 2001; Walach, Schmidt, Schneider, Seiter, \& Bösch, 2002). A meta-analysis of all these studies showed an overall significant effect of $\mathrm{d}=0.11(\mathrm{p}=.001)$. If only the more recent experiments with the best methodology were combined in a best evidence synthesis, however, the p-value dropped to a non-significant p=.50 (Schmidt, Schneider, Utts, \& Walach, 2004).

Again, we see the same pattern: a lot of intriguing results, even over a long time period that are difficult to nail down by a single experiment or by a series of tight follow-up experiments.

\section{EEG-Correlation Experiments}

The observation that EEGs of related persons although not in each other's presence might be correlated had been already reported in the 60s (Duane $\&$ 
Behrendt, 1965). This paradigm was taken up by Grinberg-Zylberbaum, who in a series of experiments stimulated individuals visually, but also acoustically, using stroboscopic lights and sounds. He recorded the event related potential by EEG, and observed a similar deviation from random activity in another spatially separated individual. Grinberg-Zylberbaum and colleagues reported what they called "transferred potentials" (Grinberg-Zylberbaum, Delaflor, Attie, \& Goswami, 1994). By that they meant that in the EEG of the nonstimulated person a smaller, but similarly shaped event-related potentials could be observed at the same time. Two unpublished reports in Dr. Fenwick's lab gave mixed evidence, one study replicating, one not replicating the result (Fenwick, Vigus, \& Sanders, 1998; Sabell, Clarke, \& Fenwick, 2001). We replicated the experiment under tight conditions, with an electromagnetic shielding between measurement chambers. We used a defined, non-electromagnetic stimulus of an inverse-flickering chequer board pattern, and controlled for the electromagnetic coupling of equipment by control runs with covered screens. Our initial experiment was strikingly positive (Wackermann, Seiter, Keibel, \& Walach, 2003), and could be replicated by further experiments that employed more subject numbers and intra-individual controls, as well as a higher resolution EEG recording (Wackermann, Naranjo, \& Puetz, 2004). Other groups also reported positive results (Radin, 2004; Standish, Kozak, Johnson, \& Richards, 2004). However, the significant effect of the latter study was driven by only 5 couples out of 60 and only one of those could replicate the effect in a second attempt. A similar pattern was visible in a follow-up study (Kozak, Standish, Johnson, Richards, \& Stewart, 2005), where four out of 16 pairs showed significant effects, but could not replicate the effect in a follow-up study.

Recently, we have conducted more follow-up studies with this paradigm. Our last two studies which were conducted over a large distance between England and Germany yielded mixed results that were certainly less clear than the initial one. However, taking all studies together and considering the many parameters we have measured and which we could not correct for, we only see a very small effect if at all. Furthermore, the effects shift between the variables and cannot be attributed to a certain EEG feature (Hinterberger, Studer, Jäger, $\&$ Walach, 2008, in press). An independent replication in the same institution as we conducted the first study, but in a different lab, using electromagnetically fully shielded chambers and a slightly more conservative analysis was unable to find any effect whatsoever (Ambach, 2009, in print). 
The analysis of a possible presentiment effect showed similar behaviour (Hinterberger, Studer, Jäger, Haverty-Stacke, \& Walach, 2007). And overall it looks again as if the initially reported effects could not be replicated. ${ }^{2}$

\section{A Common Framework for Parapsychological Effects: Generalised Non- locality}

To summarize, our argument does not say that there is no such phenomenon as an unconventional cognition or parapsychological influence. What we want to stress is that the evidence established so far is different from classically known causal effects which are stable and reproducible and hence can be isolated by replicated efforts of experimentation.

We propose that the parapsychological phenomena belong to an altogether different category of phenomena that have yet to be understood properly. An intrinsic property of these effects is exactly their elusiveness under strict experimental control but also a visibility sufficient enough to suggest they are real. We propose to call these phenomena effects of generalised non-locality (Lucadou, Römer, \& Walach, 2007; Walach, 2005; Walach \& Schmidt, 2005).

\section{Local and Non-local Correlations}

Traditional experimentation in parapsychology, following the experimental paradigm, assumes implicitly that there is a stable causal mechanism which leads to a correlation between cause and effect that can be isolated, reproduced and thus finally experimentally proven. In analogy to physics we call this a local correlation. In physics this means that any interaction between distant objects can occur maximally with the speed of light and obeys the general laws of energy exchange (Eberhard, 1978; Reichenbach, 1957). Also in analogy to physics we assume that there is another class of connection between distant

\footnotetext{
2) Some would, no doubt, cite the highly successful studies by Dean Radin (Radin, 1997) as counterexamples, where parapsychological effects seem to have been replicated. While this is true from a superficial point of view, these studies do not consist of a series of strict replications as in the paradigms discussed above. Mostly, the studies by Dean Radin are successful first shots, where a paradigm was either newly invented or adapted from existing ones, and each result was statistically significant, as a rule. But there was never any replication. On the contrary, the secret of those significant results seems to be precisely that they are not replicated (Dean Radin, personal communication, 17 th July 2007).
} 
objects which we call non-local correlations. By that term we mean correlations which are not mediated by a causal signal transfer mechanism but, similarly as in quantum physics, by the systemic make-up and the boundary conditions of a system.

Without going into details here, let us examine briefly this strange kind of correlation that can occur in a quantum system: the properties of two or more quanta can correlate in a precise way even though no transmission of energy or matter takes place between them, which means there is no causal connection.

The following conditions are necessary for this phenomenon to arise: An isolated quantum system consisting of several quanta is characterised by one fixed global observable which defines the system as a whole and which is subject to a conservation law. At the same time the states of the individual quanta which collectively constitute this global observable are completely unpredictable until they are determined by measurement. As an example, a system consisting of two photons A and B may be defined by a global observable of zero spin, while the individual photons cannot be attributed definite spins but could, upon measurement, assume states of positive or negative spin just as long as they collectively add up to zero. The formalism of Quantum Theory allows for describing this situation via a wave-function which includes all possible states of the individual quanta but does not define which of the possible states will be assumed by the quanta upon measurement. Once the precise state of one or several of the individual quanta is determined by measurement, the other quantum also takes on a particular state in such a way that the global observable is conserved. Thus the system behaves in a correlated fashion, and this collapse of the system into a certain state is instantaneous and can extend even over large distances, without exchange of signals or energy. This strange correlatedness of elements of a quantum system has been termed entanglement by Schrödinger (Schrödinger, 1935), and is also known as EPR-correlatedness after Einstein, Podolsky and Rosen who have tried to use it as an argument against the plausibility of quantum mechanics (Einstein, Podolsky, \& Rosen, 1935). However, after experimental testing, quantum mechanics was vindicated and it has been generally accepted for quite a while now that entanglement in quantum systems is a real phenomenon (Aspect, Dalibard, \& Roger, 1982; Aspect, Grangier, \& Roger, 1982; Gröblacher et al., 2007; Zeilinger, 1999).

We have suggested an algebraic formalism which is a generalised version of quantum mechanics, and hence applicable to other systems as well (Atmanspacher, Römer, \& Walach, 2002). Its basic feature is that restrictions and defi- 
nitions typical for quantum mechanics are dropped, but one central element is kept: non-commuting operations are still defined. These are formalisations of operations that are mutually incompatible. Thereby, this generalised version of quantum mechanics, Weak Quantum Theory (WQT), predicts entanglement in the system described, similar to quantum mechanics proper. This entanglement can be expected to occur if descriptions of the system that pertain to the whole system are complementary to descriptions of parts of the system. In that case the individual elements within the system that are described by variables complementary to the variable describing the whole system are non-locally correlated.

It is very important to note at this point that these predicted entanglement correlations are not EPR-correlations in the strict sense, but generalised entanglement correlations, theoretically predicted by the generalised formalism of WQT. Hence the argument normally levelled against attempts of using quantum mechanics proper to explain macroscopic phenomena in the real worldthe question of decoherence of EPR-correlations due to multiple interactions in macroscopic systems - is not valid for the generalised case. However it is necessary to acknowledge that the generalised case of entanglement correlations predicted by WQT is purely hypothetical at this point.

\section{Complementarity}

This effect of non-local correlatedness within a system according to the formalism of WQT hinges on the complementarity between global and local variables. In quantum mechanics complementarity is well defined and formally expressed by non-commuting operators. Weak quantum theory uses the same formal expression of non-commuting operators. However, the translation from the formalism into reality is more difficult in WQT. We have little understanding of what complementarity and non-commutativity may mean on a macroscopic non-quantum level, let alone in everyday language (Bedau \& Oppenheim, 1961; beim Graben \& Atmanspacher, 2006; Bohr, 1937; Walach \& Römer, 2000). It does not refer to simple opposites, where one element can be expressed by negating the other, such as in "hot" and "cold". It rather refers to maximally incompatible descriptions that are necessary to describe one reality (Meyer-Abich, 1965). The famous example in the quantum world is the double nature of light photons, which can be experimentally described either as a wave or as a particle. In the case of describing them by means of a wave, we have rather clear information about their momentum, but practically no information about their location. Alternatively, light can be described as photon particles. In that case we can precisely locate them, but 
lose all information about their momentum. Thus, both descriptions seem to be necessary in order to fully grasp the double character of the photon.

It is not easy to translate this situation into our everyday language and into systems that are familiar to us. One way of doing so is using the complementary notion of connectedness and separation, or individuality and community. Both are necessary to describe the phenomenal reality, in which human experience is embedded, but neither is sufficient on its own, nor can they be reduced to each other. Individuality is more than simply not being in communion and not being connected. And connectedness or community does not mean to completely lose one's individuality. Here we have perhaps natural language descriptions that come closest to complementary pairs of descriptions as we know them from quantum mechanics.

If this is true, then we would expect some non-local correlations, following the formalism of WQT, in systems that can be described in terms of these complementary variables. In such a case WQT predicts non-local correlations between individual elements of the system. There might be other conditions governing the set-up of such non-local correlations in larger systems which we do not understand at present. Gernert, for example, has proposed that there needs to be something actively joining the elements in order to allow them to act like a holistic system by means of non-causal effects, such as a common history, or a joint future (Gernert, 2005, 2008), and von Lucadou has emphasised the importance of systemic boundaries (Lucadou, 1995).

If these assumptions are borne out then we would expect non-local correlations to be quite ubiquitous. So called parapsychological effects might be instances, where they can be seen more clearly, and we assume that most, if not all the effects parapsychology investigates are actually due to such generalised non-local effects or generalised entanglement.

\section{The Impossibility of Information Transfer}

In that case the empirically observed pattern of non-reproducibility is not surprising, but actually exactly what would be expected. For all effects based on entanglement correlations have one property in common: they can by no means be used to transmit signals. Signal transmission here can be defined as the possibility to infer the state of a distant part of the universe solely from the observation of one of the entangled subsystems. For the case of quantum mechanics it is quite clear that such a situation can never arise, because while the states of entangled quanta are precisely correlated they are on both sides of the correlation completely independent of their environment. Recalling the 
example of entangled photons $A$ and $B$, this means that when a certain state of $\mathrm{B}$ is determined by measurement one can immediately infer the state of A even if it is far away, but this will not convey any information about the surroundings of A because the states of A and B manifest themselves completely independently from their respective environment. (For a formal proof of this see the Appendix in (Lucadou, Römer, \& Walach, 2007)). This independence becomes apparent as the absolute unpredictability of the measurement outcomes. As soon as this unpredictability is reduced through measurement or manipulation, decoherence occurs and the correlation will be no longer detectable.

For the case of WQT this is less straightforward, but can be assumed as a theorem. If this theorem is true we would expect generalised entanglement correlations to break down (become undetectable) in systems where they could otherwise in principle be used to transmit signals. Direct replications of experiments can actually be thought to constitute such systems. Why? One could imagine that the results of an experiment, where an experimental condition is tested against a control, would result in a significant difference. In a replication experiment, such information could be used to predict the group assignment. In other words, by solely observing one part of the system one is able to infer something about the state of the surroundings of another part of the system, thus a signal has been transmitted via the system. If our assumptions are right the non-causal correlations of generalised entanglement will no longer be stably detectable under such conditions.

Hence the actual pattern that is generated by effects due to generalised entanglement would be exactly the one observed in parapsychology: strong initial effects that cannot be replicated, but turn into strong negative ones, or decay and resurface again with further replication, with a clear lack of stability.

We have therefore argued that such effects are likely due to such generalised non-locality and hence they will defy direct experimental manipulation. No experimental series, no matter how good and how long, how expensive and how well done will succeed in isolating these effects in the long run. This will not preclude the occurrence of single strong, even spectacular effects as they are well known from first-hand phenomenological reports. Contrary to quantum mechanics proper, WQT does not define the commutation relationship. In quantum mechanics this role is taken over by Planck's constant, and thereby this commutator also defines the upper boundary such entanglement correlations can have in quantum mechanics proper. In WQT this commutator is as yet undefined, and it is conceivable that such correlations might be also quite 
strong in single cases. This could explain really massive events such as strong haunting or poltergeist phenomena. But replications within experimental paradigms are bound to be unsuccessful in the long run, and this is exactly the situation which we face in experimental parapsychology.

As yet, we are not sure whether there is a remedy. We have suggested pursuing meta-experiments, which are sensitive to the boundary conditions of nonlocal effects. It might be necessary, for instance, rather than comparing such effects directly against controls to use a design were a target variable, say intention, could be correlated to an orthogonal variable, such as the potential states of mood of the experimenter, etc. We would anticipate more significant correlations than expected by chance, but not a stable pattern of correlations. One should always keep in mind that in the quantum case the reality of entanglement correlations is not proven directly by comparing results of an experiment against a control condition, but by testing the outcome of a long series of measurements against a theoretical expectation derived from a combinatorial argument leading to Bell's inequalities (Bell, 1987). For the generalised version no such argument has been formulated as yet, and hence there is no way of testing an outcome against a theoretical expectation. What is more, there may be fundamental differences between the situation in quantum physics and in macroscopic systems, which might make it in principle impossible to create a macroscopic analogue to the kind of experimental system which helped to prove the existence of non-causal correlations between quanta. One candidate for such a fundamental difference is for example that in macroscopic systems it is impossible to create completely unpredictable states.

It is important to note that experimental conceptualisations within parapsychology have predominantly focussed on the possibility of the conscious or unconscious character of the effect, but not systematically questioned the causal-mechanistic character of the alleged psi-phenomena. We also should be aware that possibly the non-signal transfer observation in these experiments applies to complementary variables only. Generally, the concept of generalized entanglement should not be per se applied to all irreproducible results, as there can also be quite trivial reasons for non-replicability.

But if the general thrust of the argument is true then no amount of direct experimentation will succeed in isolating the effects, because it will be precisely the attempt at isolating them that will destroy them. Reverting back to our larger historical perspective we can now see the backlash of the subtle dialectics: by using the methodology of natural science parapsychology may actually have destroyed the scientific viability of the very effects it wanted to vindicate. We can now also see why: because these effects are very likely alto- 
gether of a different nature in the first place. By mistaking these effects as the same in kind, only perhaps more subtle and more fickle than conventional causal-local effects, parapsychology has not done them justice. Not only has it lost its way in terms of the original emphasis and purpose of its founders. But by adopting the method of direct experimentation it has almost destroyed its own subject matter.

What is the solution? We propose that it is time to refocus. If the effects are seen as effects of generalised entanglement then something strange happens: spirituality creeps back in to the agenda of parapsychology, and indeed of the scientific enterprise at large.

\section{Generalised Non-locality is at the Core of Spirituality}

Spirituality is the experiential realisation of a transcendent reality (Ferrer, 2002; Fontana, 2003; Hill \& Pargament, 2003; Kohls \& Walach, 2006; Miller \& Thoresen, 2003; Walach, 2007; Walach \& Reich, 2005). This is variably called meaning or purpose, sometimes it is called a relationship with a transcendent goal or reality reaching beyond the ego. We have seen in the Introduction that spirituality has at least two core aspects:

It refers to a relationship with a reality that reaches beyond the ego. The second aspect is about its experiential manifestation, i.e. a holistic type of knowing that includes cognition, affect and motivation.

The relationship of spirituality to religion can be, briefly, defined as that of content to form. Where religion provides a form of teachings, doctrines, rules for behaviour and rituals for expressing experience and facilitating it, spirituality refers to the actual experience. Each religion has its own spiritual tradition, sometimes called mystical tradition, and each spiritual tradition can normally be referred back to a religious form or will eventually create one (Forman, 1998). Each of these traditions has a particular type of practice to offer that allows their followers to move on and grow in their experience, while the religious form supplies social organization and structure as well as the cultural and contextual containment of these experiences in the form of images, metaphors, parables, myths and rituals.

Central to all these traditions seems to be the experiential realisation of some kind of unity with a larger reality. In Christian mysticism this is called unio mystica, and the assumption is that here a part of the soul is united with God. In Buddhist traditions the experiential realisation is about oneness with all being and about the emptiness of forms, which is at the same time fullness. 
In other traditions the unity is with nature, with ancestors, with the group, with other deities. Often this unity is enacted in prayer and meditation, the latter being more of a receptive kind of practice and prayer being more active. In prayer the individual seeks to bring into reality wishes, either for oneself or for others. In meditation the individual seeks to be united or filled with the transcendent reality.

Each spiritual tradition also knows of experiences similar to parapsychological phenomena that are likely to occur on the spiritual path (Eliade, 1975). As one is progressing to the goal of unification, one will have experiences of telepathic oneness with others, anomalous information transfer or even psychokinetic experiences. These are not regarded as surprising, but also not as a goal. In the Christian tradition they are known as signs of holiness in a lot of the traditional trials of sanctification (Thurston, 1952), but they are not regarded as essential or desirable. For instance, miraculous healing through laying on of hands or simply through wishing seems to have been a signature of Christian saints from the time of the historical Jesus onwards (Douglas-Klotz, 1999), who presented himself as a healer to the public, before any preaching and teaching.

If we now assume that generalised entanglement is a rather general and ubiquitous process as suggested by the model of WQT, then we have a rather natural understanding at hand. Such effects as healing, as telepathic connections or psychokinetic influences would be the natural result of entanglement correlations within a natural system. The systems in question would always include the conscious activity of a person that strives to be aligned with a higher, transcendent reality, thereby creating both the feeling of wholeness and connectedness. This alignment of an individual with a whole would, by necessity and as per definition of WQT, lead to a non-local correlatedness between the individual and the whole. For "part" and "whole" are similarly complementary notions as "individual/community" and "connectedness/separation" (Stillfried \& Walach, 2006). We can therefore assume that an alignment of the "part", in that case a particular individual's consciousness, with a "whole", in that case some absolute, transcendent reality, would generate or reinforce such a non-local correlation also with other "parts" of the "whole", or with other individuals. The Chinese tradition, for example, has a specific term for that: "Chi". ${ }^{3}$ Hence it is not surprising that in this tradition the practice of such

\footnotetext{
3) Although "Chi" is often referred to as "energy", it can be reconceptualised along the lines indicated here and would then signal an alignment of the individual with the whole, which seems to be closer to the original meaning anyway.
} 
alignment is supposed to go hand in hand with the increase of "supernatural" or "special" powers assumed to be due to a special force or energy. Within the framework suggested here there would not be a special unknown power at operation, but only a better non-local correlatedness between and within elements of a system, which is made possible through a distinct state of consciousness.

One could speculate that the ultimate oneness as experienced by some mystics is in fact an experiential alignment of one individual consciousness with the totality. Such an experiential realisation of oneness would be in fact an instance of super-correlatedness in our terminology. But apart from such speculation it would make sense, in the terminology adopted here, to assume that spiritual practices such as meditation or regular contemplation and prayer actually operate via the enhancement of some generalised correlatedness between an individual and the whole and thereby between the individual and other individuals. Hence, they should also facilitate such experiences of correlation with the whole, which subjectively manifest as paranormal experiences, telepathy, precognition, or synchronistic events.

If this is at all plausible, then we could bring the pieces together in a brief factual description of what spirituality means: an increase in non-local connectedness between an individual and the totality, and by the very same token also between the individual and its own subsystems and other individuals. So called anomalous events are nothing but a natural side effect of this increased non-local correlatedness. Hence, generalised entanglement would be a paradigm bridging the gap between spirituality and science, and parapsychology would be one instance within a larger picture.

\section{Conclusion and Summary: Spirituality and Research into Spirituality is the Legitimate Heir of Parapsychology}

We are now back, where we started. Spirituality as conceived here is the legitimate heir of what the founding fathers of parapsychology had in mind. They were after finding proof that an exclusive materialist description of the universe is incomplete and assumed that consciousness and mind have some real influence. Parapsychology set out to find the proof for this statement, thereby using the methodological approach of the natural sciences. It came up with a very rich but also very inconsistent database. This database makes sense when viewed in the light of generalised non-locality as described above. If this interpretation is correct then no amount of direct experimentation would be able 
to provide the definite proof for the effects under consideration. According to our theory direct experiments destroy the effects of generalised entanglement correlations. A scientific proof, if at all possible, will only be feasible using indirect methods that have yet to be derived.

Entanglement correlations in a generalised sense would also lend themselves naturally to understanding what spiritual traditions try to achieve, namely alignment of an individual consciousness with a totality. Hence parapsychology and spirituality have something in common: i.e. the processes and mechanisms at the base of what they are studying or trying to achieve. Generalised entanglement could be the overarching framework of a systemic description for both of them. Please note that this description is strictly secular as it does not make any claims about the nature of this totality. All it does is make a plausible assumption that there is some universality or totality, and the rather trivial observation that everything that is within this totality is by definition a part of this whole. Furthermore, it states that by definition these elements are complementary, and hence entanglement correlations are expected to occur.

Using our interpretation parapsychology would probably only win: it would link its effort with a larger and growing community of researchers that are interested in spirituality and its effects. It would potentially find a way out of the experimental conundrum of lack of replicability. And it would adopt a potentially powerful theoretical tool, the formalism of Weak Quantum Theory that allows for the description and understanding of the effects found in many parapsychological experiments.

The same is true for spirituality: using this approach, it can muster the full conceptual force of science and connect to its very centre. Here we discover that the scientific approach to unveil the very roots of matter lead to the same source that might be at the root of spirituality. Furthermore, this approach would allow us to actually re-interpret religious rituals in a naturalistic and strong sense. They would be rituals constituting a boundary of systems within which a stronger non-local correlatedness might occur.

With all the praise some caveats should not be forgotten: the interpretation of the formalism of WQT is still unclear in some areas. It only defines necessary but not sufficient conditions. This means that thus far it can only explain after the fact that non-local correlations were to be expected. This is sufficient for a general explanation, as it allows for a rational reconstruction of many phenomena. However, it is not sufficiently detailed to describe precisely when such effects are to be expected and, furthermore, exactly when they will break down. Also, the definition of complementary variables on a macroscopic level 
is all but precise at present. The notions of 'part' and 'whole', or 'individual' and 'community' have as yet still a rather intuitive meaning only. But it is at least rational to conceive a future state where such definitions are clearer, and hence also easier to understand under which conditions some individual will be expected to be in non-local correlation with other individuals within a certain system. But for now we will have to be satisfied with this rather loose description. Even so this attempt at modelling can make two things plausible: parapsychological events can be reconstructed rationally as effects of non-local correlatedness to be expected in systems under certain conditions. Spirituality is a concept capable of encompassing parapsychological effects and can be construed as operating on the same basic principles of generalised non-locality. Thus Generalised Entanglement might be a powerful global concept that affords us with what the founding fathers of parapsychology sought in vain: a scientific notion that allows for a non-reductive understanding of spirituality, parapsychology and human nature, while at the same time being scientific and connected to the mainstream of science.

\section{Acknowledgements}

HW, NK, TH, NvS and SS received funding for their research from the Samueli Institute. NK, TH \& SS are currently Samueli-Rockefeller Scholars funded by the Samueli-Rockefeller Program Brain, Mind and Healing at the Samueli Institute.

\section{References}

Alcock, J.E. (2003). Give the null hypothesis a chance: Reasons to remain doubtful about the existence of PSI. Journal of Consciousness Studies, 10(6-7), 29-50.

Ambach, W. (2009, in print). Correlations between the EEGs of two spatially separated subjects-a replication study. European Journal of Parapsychology, in print.

Aspect, A., Dalibard, J., \& Roger, G. (1982). Experimental test of Bell's inequalities using time varying analyzers. Physics Review Letter, 49, 1804-1807.

Aspect, A., Grangier, P., \& Roger, G. (1982). Experimental realization of Einstein-PodolskyRosen-Bohm-Gedankenexperiment: A new violation of Bell's inequalities. Physics Review Letter, 49, 91-94.

Atmanspacher, H., Bösch, H., Boller, E., Nelson, R.D., \& Scheingraber, H. (1999). Deviations from physical randomness due to human agent intention? Chaos, Solitons and Fractals, 10, 935-952. 
Atmanspacher, H., Römer, H., \& Walach, H. (2002). Weak quantum theory: Complementarity and entanglement in physics and beyond. Foundations of Physics, 32, 379-406.

Bauer, E. (1997). Gegen den Strom schwimmen: Hundert Jahre parapsychologischer Forschung [Swimming against the current: A century of parapsychological research]. In v. Lucadou, W., editor, Psi-Phänomene: Neue Ergebnisse der Psychokinese-Forschung [Psi Phenomena: New Results of Research into Psychokinesi]. Frankfurt am Main/Leipzig: Insel Verlag (insel taschenbuch 2109).

Bedau, H., \& Oppenheim, P. (1961). Complementarity in quantum mechanics: A logical analysis. Synthese, 13, 201-232.

beim Graben, P., \& Atmanspacher, H. (2006). Complementarity in classical dynamical systems. Foundations of Physics, 36(2), 291-306.

Bell, J.S. (1987). Speakable and unspeakable in quantum mechanics. Cambridge: Cambridge University Press.

Beloff, J. (1993). Parapsychology: A concise history. London: Athlone Press.

Bohr, N. (1937). Causality and complementarity. Philosophy of Science, 4, 289-298.

Bösch, H., Steinkamp, F., \& Boller, E. (2006a). Examining psychokinesis: The interaction of human intention with random number generators-a meta-analysis. Psychological Bulletin, $132,497-523$.

Bösch, H., Steinkamp, F., \& Boller, E. (2006b). In the eye of the beholder: Reply to Wilson and Shadish (2006) and Radin, Nelson, Dobyns, and Houtkooper (2006). Psychological Bulletin, 132(4), 533-537.

Braud, W., \& Schlitz, M. (1983). Psychokinetic influence on electrodermal activity. Journal of Parapsychology, 47, 95-119.

Collingwood, R.G. (1998, orig. 1940). An essay on metaphysics (revised ed.). Oxford: Clarendon Press.

Damasio, A. (2000). The feeling of what happens. Body, emotion, and the making of consciousness. London: Vintage.

Daniels, M. (Ed.). (2005). Shadow, self, spirit: Essays in transpersonal psychology. Charlottesville, VA: Imprint Academic.

Dennett, D.C. (1991). Consciousness Explained. Boston: Little, Brown \& Co.

Dilthey, W. (1910 (orig. 1894)). Ideen über eine beschreibende und zergliedernde Psychologie. In Gesammelte Schriften (Vol. 5, pp. 139-239). Leipzig: Teubner.

Docket, K.H., Dudley-Grant, G.R., \& Bankart, C.P. (Eds.). (2003). Psychology and Buddhism: From Individual to Global Community. New York, Boston: Kluwer Academic/Plenum Publishers.

Douglas-Klotz, N. (1999). The hidden gospel. Decoding the spiritual message of the Aramaic Jesus. Wheaton, Il: Quest Books.

Du Bois-Reymond, E. (1918). Jugendbriefe von Emile DuBois-Reymond an Eduard Hallmann. Berlin: Dietrich Reiner. 
Duane, T.D., \& Behrendt, T. (1965). Extrasensory electroencephalographic induction between identical twins. Science, 150, 367.

Dunne, B.J., \& Jahn, R. G. (2005). Consciousness, information, and living systems. Cellular and Molecular Biology, 51, 703-714.

Eberhard, P. (1978). Bell's theorem and the different concepts of locality. Nuovo Cimento, 46B, 392-419.

Einstein, A., Podolsky, B., \& Rosen, N. (1935). Can quantum-mechanical description of reality be considered complete? Physical Review, 47, 777-780.

Eliade, M. (1975). Patanjali and Yoga. New York: Schocken Books.

Ertel, S. (2007). Kritischer Kommentar zu einer Meta-Analyse von Bösch, Steinkamp \& Boller: Examining psychokinesis: The interaction of human intention with random number generators-A meta-analysis” Psychological Bulletin 2006 132,497-523. Zeitschrift für Anomalistik, 6 , in print.

Fenwick, B.C.P., Vigus, N., \& Sanders, S. (1998). The transferred potential: Maudsley Hospital, Neurobiology Lab.

Ferrer, J.N. (2002). Revisioning transpersonal theory: A participatory vision of human spirituality. Albany: SUNY Press.

Fontana, D. (2003). Psychology, religion, and spirituality. Malden, Mass: BPS Blackwell.

Forman, K.C. (Ed.). (1998). The innate capacity : Mysticism, psychology, and philosophy Oxford: Oxford University Press.

French, C.C. (2003). Fantastic memories: The relevance of research into eyewitness testimony and false memories for reports of anomalous experiences. Journal of Consciousness Studies, 10(6-7), 153-174.

Gauld, A. (1968). The founders of psychical research. London: Routledge \& Kegan Paul.

Gernert, D. (2005). Conditions for entanglement. Frontier Perspectives, 14(2), 8-13.

Gernert, D. (2008). How to initiate and to disturb entanglement. In Dubois, D.M., editor, Computing anticipatory systems; AIP Proceedings (Vol. 1051, pp. 76-81). Melville, NY: American Institute of Physics.

Grinberg-Zylberbaum, J., Delaflor, M., Attie, L., \& Goswami, A. (1994). The Einstein-Podolsky-Rosen paradox in the brain: the transferred potential. Physics Essays, 7, 422-427.

Gröblacher, S., Paterek, T., Katenbaek, R., Brukner, C., Zukowski, M., Aspelmeyer, M., et al. (2007). An experimental test of non-local realism. Nature, 446, 871-875.

Grossman, P., Schmidt, S., Niemann, L., \& Walach, H. (2004). Mindfulness based stress reduction and health: A meta-analysis. Journal of Psychosomatic Research, 37, 35-43.

Hergovich, A. (2005). Der Glaube an Psi: Die Psychologie paranormaler Überzengungen [Belief in Psi: The psychology of paranormal beliefs] (2nd edition). Bern: Huber.

Hill, P.C., \& Pargament, K.I. (2003). Advances in the coneptualization and measurement of religion and spirituality: Implications for physical and mental health research. American Psychologist, 58, 64-74. 
Hinterberger, T., Studer, P., Jäger, M., Haverty-Stacke, C., \& Walach, H. (2007). The slide-show presentiment effect discovered in brain electrical activity. Journal of the Society of Psychical Research, 71, 148-166.

Hinterberger, T., Studer, P., Jäger, M., \& Walach, H. (2008, in press). Event-related correlations between brain electrical activities of separated human participants. International Journal of Neuroscience.

Ineichen, H. (1985). Wilhelm Dilthey. In Höffe, O., editor, Klassiker der Philosophie II: Von Immanuel Kant bis Jean-Paul Sartre (2. Aufl. ed., pp. 187-202). München: Beck.

Inglis, B. (1977). Natural and supernatural: A history of the paranormal from earliest times to 1914. London: Hodder and Stoughton.

Inglis, B. (1984). Science and parascience: A history of the paranormal, 1914-1939. London: Hodder and Stoughton.

Jahn, R.G., \& Dunne, B.J. (1987). Margins of reality. The role of consciousness in the physical world. San Diego: Harcourt Brace Jovanovich.

Jahn, R.G., Dunne, B.J., Bradish, G.J., Dobyns, Y.H., Lettieri, A., Nelson, R.D., et al. (2000). Mind/machine interaction consortium: PortREG replication experiments. Journal of Scientific Exploration, 14, 499-555.

James, W. (1985). The works of William James. The varieties of religious experience. Cambridge, MA: Harvard University Press.

Koenig, H.G. (Ed.). (1998). Handbook of religion and mental health. San Diego: Academic Press.

Koenig, H.G., McCullough, M.E., \& Larson, D.B. (Eds.). (2001). Handbook of religion and health. New York: Oxford University Press.

Kohls, N., \& Walach, H. (2006). Exceptional experiences and spiritual practice: A new measurement approach. Spirituality and Health International, 7, 125-150.

Kozak, L., Standish, L.J., Johnson, C., Richards, T., \& Stewart, B.K. (2005). Evidence of brain correlations between isolated human subjects: Electroencephalographic (EEG) study in a population of experienced meditators. Paper presented at the The Parapsychological Association 48th Annual Convention.

Larson, D.B., \& Larson, S.S. (2003). Spirituality's potential relevance to physical and emotional health: A brief review of quantitative research. Journal of Psychology and Theology, 31, 37-51.

Larson, E.J., \& Witham, L. (1998). Leading scientists still reject god. Nature, 394, 313.

Lenoir, T. (1989). The strategy of life: Teleology and mechanics in nineteenth-century German biology. Chicago: University of Chicago Press.

Mason, M.F., Norton, M.I., Van Horn, J.D., Wegner, D.M., Grafton, S.T., \& Macrae, N. (2007). Wandering minds: The default network and stimulus-independent thought. Science, 315, 393-395.

Mauskopf, S.H., \& McVaugh, M.R. (1980). The elusive science: Origins of experimental psychical research. Baltimore: Johns Hopkins University Press. 
Meyer-Abich, K.M. (1965). Korrespondenz, Individualität und Komplementarität. Wiesbaden: Steiner.

Miller, W.R., \& Thoresen, C.E. (2003). Spirituality, religion, and health: An emerging field. American Psychologist, 58, 24-35.

Mumford, M.D., Rose, A.M. and Goslin, D.A. (1995). "An Evaluation of Remote Viewing: Research and Applications." Review of the Department of Defense's STAR GATE Program (retrieved 13. Aug. 2008, from www.fas.org/irp/program/collect/air1995.pdf)

Nelson, R.D., Jahn, R.G., Dobyns, Y.H., \& Dunne, B.J. (2000). Contributions to variance in REG experiments: ANOVA models and specialized subsididary analyses. Journal of Scientific Exploration, 14, 73-89.

Pallikari, F. (2001). A study of the fractal character in electronic noise process. Chaos, Solitons and Fractals, 12, 1499-1507.

Paul, R. (1984). German academic science and the Mandarin ethos, 1850-1880. The British Journal for the History of Science, 17, 1-29.

Pratt, J., Rhine, J., Smith, B., Stuart, C., \& Greenwood, J. (1966). Extrasensory perception after sixty years. Boston, Mass: Bruce Humphries.

Radin, D. (1997). The conscious universe. The scientific truth of psychic phenomena. San Francisco: Harper Collins.

Radin, D. (2004). Event-related eletroencephalographic correlations between isolated human subjects. Journal of Alternative and Complementary Medicine, 10, 315-323.

Radin, D., \& Nelson, R.D. (1989). Evidence for consciousness-related anomalies in random physical systems. Foundations of Physics, 19, 1499-1514.

Radin, D., \& Nelson, R.D. (2003). Research on mind-matter interactions (MMI): individual intention. In Jonas, W.B. \& Crawford, C., editors, Healing intention and healing energy medicine. Science, research methods and clinical implicatins. Edinburgh: Churchill Livingstone.

Radin, D., Nelson, R.D., Dobyns, Y.H., \& Houtkooper, J.M. (2006). Reexamining psychokinesis: Comment on Bösch, Steinkamp, and Boller (2006). Psychological Bulletin, 132(4), 529532.

Raichle, M.E. (2006). The brain's dark energy. Science, 314, 1249-1250.

Reichenbach, H. (1957). The philosophy of space and time. New York: Dover.

Rhine, J. (1964). Extrasensory perception. Boston, Mass: Branden.

Sabell, A., Clarke, C., \& Fenwick, B.C.P. (2001). Inter-subject EEG correlations at a distancethe transferred potential. In The Parapsychological Association 44th Annual Convention. Proceedings of Presented Papers. (pp. 419-422). Durham, NC: The Parapsychological Association.

Schlitz, M., \& Braud, W. (1997). Distant intentionality and healing: Assessing the evidence. Alternative Therapies in Health and Medicine, 3, 38-53.

Schmidt, S., Schneider, R., Binder, M., Bürkle, D., \& Walach, H. (2001). Investigating methodological issues in EDA-DMILS: Results from a pilot study. Journal of Parapsychology, 65, 59-82. 
Schmidt, S., Schneider, R., Utts, J., \& Walach, H. (2004). Remote intention on electrodermal activity-Two meta-analyses. British Journal of Psychology, 95, 235-247.

Schmidt, S., Tippenhauer, G., \& Walach, H. (2001). Connectedness between participants in an experiment on distant intention. In The Parapsychological Association 44th Annual Convention. Proceedings of Presented Papers (pp. 285-300). Durham, NC: The Parapsychological Association.

Schmidt, S., \& Walach, H. (2000). Electrodermal activity (EDA)—State of the art measurement and techniques for parapsychological purposes. Journal of Parapsychology, 64, 139-163.

Schneider, R., Binder, M., \& Walach, H. (2000). Examining the role of neutral versus personal experimenter-participant interactions: An EDA-DMILS experiment. Journal of Parapsychology, 64, 181-194.

Schneider, R., Binder, M., \& Walach, H. (2001). A two-person effort: On the role of the agent in DMILS experiments. European Journal of Parapsychology, submitted.

Schrödinger, E. (1935). Discussion of probability relations between separated systems. Proceedings of the Cambridge Philosophical Society, 31, 555-563.

Segal, Z.V., Williams, J.M.G., \& Teasdale, J.D. (2002). Mindfulness-based cognitive therapy for depression: a new approach to preventive relapse. New York: Guilford Press.

Sheldrake, R. (2001). Experiments on the sense of being stared at: the elimination of possible artefacts. Journal of the Society for Psychical Research, 65, 122-137.

Sheldrake, R., \& Smart, P. (2000). A dog that seems to know when his owner is coming home: videotaped experiments and observations. Journal of Scientific Exploration, 14, 233-255.

Sheldrake, R., \& Smart, P. (2003). Videotaped experiments on telephone telepathy. Journal of Parapsychology, 67, 187-206.

Smallwood, J., \& Schooler, J.W. (2006). The restless mind. Psychological Bulletin, 132, 946-958.

Society for Psychical Research. (1882). Objects of The Society. Proceedings of the Society for Psychical Research, 1, 3-6.

Sonntag, M. (2001). Vermessung der Seele-Zur Entstehung der Psychologie als Wissenschaft. In van Dümen, R., editor, Entdeckung des Ich -Die Geschichte der Individualisierung vom Mittelalter bis zur Gegenwart. Köln, Weimar \& Wien: Böhlau.

Standish, L.J., Kozak, L., Johnson, L.C., \& Richards, T. (2004). Electroencephalographic evidence of correlated event-related signals between the brains of spatially and sensory isolated human subjects. Journal of Alternative and Complementary Medicine, 10, 307-314.

Thurston, H.H.C. (1952). The Physical Phenomena of Mysticism. London: Burns Oats.

Timm, U. (2007). Kommentar zu Bösch, H., Steinkamp, F. \& Boller, E: "Examining psychokinesis a meta-analysis." Psychological Bulletin, Vol. 132, 2006. Zeitschrift für Anomalistik, 6(in print).

Toulmin, S. (1985). Conceptual revolutions in science. In Cohen, R.S. \& Wartofsky, M.W., editors, A portrait of twenty-five years: Boston Colloquium for the philosophy of science 19601985. Dordrecht: Reidel. 
Treitel, C. (2004). A science for the soul. Occultism and the genesis of the german modern. Baltimore \& London: Johns Hopkins University Press.

Utts, J. (1996). An assessment of the evidence for psychic functioning. Journal of Scientific Exploration, $10,3-39$.

Von Lucadou, W. (1995). The model of pragmatic information (MPI). European Journal of Parapsychology, 11, 58-75.

Von Lucadou, W. (2001). Hans in Luck: The currency of evidence in parapsychology. Journal of Parapsychology, 65, 3-16.

Von Lucadou, W., Römer, H., \& Walach, H. (2007). Synchronistic phenomena as entanglement correlations in generalized quantum theory. Journal of Consciousness Studies, 14, 50-74.

Von Stillfried, N., \& Walach, H. (2006). The whole and its parts: Are complementarity and nonlocality intrinsic to closed systems? International Journal of Computing Anticipatory Systems, 17, 137-146.

Wackermann, J., Naranjo, J.R.M., \& Puetz, P. (2004). Event-related correlations between brain electrical activities of separated human subjects: preliminary results of a replication study. Paper presented at the The 47 th Annual Convention of the Parapsychological Association. Proceedings of presented papers.

Wackermann, J., Seiter, C., Keibel, H., \& Walach, H. (2003). Correlations between brain electrical activities of two spatially separated human subjects. Neuroscience Letters, 336, 60-64.

Walach, H. (2005). Generalized entanglement: A new theoretical model for understanding the effects of complementary and alternative medicine. Journal of Alternative and Complementary Medicine, 11, 549-559.

Walach, H. (2007). Mind-body—spirituality. Mind and Matter, 5, 215-240.

Walach, H., \& Jonas, W.B. (2007). From parapsychology to spirituality: The legacy of the PEAR database. Explore. The Journal of Science and Healing, 3, 197-199.

Walach, H., \& Reich, K.H. (2005). Science and spirituality: Towards understanding and overcoming a taboo. Zygon, 40, 423-441.

Walach, H., \& Römer, H. (2000). Complementarity is a useful concept for consciousness studies. A reminder. Neuroendocrinology Letters, 21, 221-232.

Walach, H., \& Schmidt, S. (2005). Repairing Plato's life boat with Ockham's razor: The important function of research in anomalies for mainstream science. Journal of Consciousness Studies, $12(2), 52-70$.

Walach, H., Schmidt, S., Schneider, R., Seiter, C., \& Bösch, H. (2002). Melting boundaries: Subjectivity and intersubjectivity in the light of parapsychological data. European Journal of Parapsychology, 17, 72-96.

Wallace, B.A., \& Shapiro, S.L. (2006). Mental balance and well-being: Building bridges between Buddhism and Western psychology. American Psychologist, 61(7), 690-701.

Williams, M., Teasdale, J., Segal, Z., \& Kabat-Zinn, J. (2007). The mindful way through depression: Freeing yourself from chronic unhappiness. New York: Guilford Press. 
Wilson, D.B., \& Shadish, W.R. (2006). On blowing trumpets to the tulips: To prove or not to prove the null hypothesis-comment on Bösch, Steinkamp, and Boller (2006). Psychological Bulletin, 132(4), 524-528.

Wiseman, R., \& Morris, R.L. (1995). Guidelines for testing psychic claimants. Hatfield: University of Hertfordshire Press.

Wiseman, R., \& Schlitz, M. (1997). Experimenter effects and the remote detection of staring. Journal of Parapsychology, 61, 197-208.

Wolf, J. (1995). Psychic power real, but no good for spying, CIA says. Reuters, Washington, November 29,1995

Zeilinger, A. (1999). A foundational principle for quantum mechanics. Foundation of Physics, 29, 631-643. 